\title{
Design for me?
}

\author{
Charlotte Magnusson $^{1}$, Per-Olof Hedvall ${ }^{1}$, and Björn Breidegard ${ }^{1}$ \\ ${ }^{1}$ Lund University, PO Box 118, 221 00, Lund, Sweden
}

\begin{abstract}
In this paper, as a generative contrast to the notion of design "for all", we present and discuss the potential benefits of a design "for me" approach, where the design process from the starts from, and initially is targeted at, just one person. Given many things developed for a user group or a constructed average user, in this text we describe starting from design for a single user as an alternative approach for achieving useful and useworhty designs. We provide an example from the development of an assistive device as the starting point and discuss how and why this alternative approach should be of interest for everyone interested in usability.
\end{abstract}

Keywords: Design, user-centered, method.

\section{Introduction}

This paper deals with the ever-increasing interest for Design for All and ways of gaining better understanding of different users and their lives. As a generative contrast to the notion of "for all" we present and discuss the potential benefits of a "for me" approach, where the design process from the start and on is targeted at just one person. The research is based on a ten-year development of an assistive communication system for a girl suffering from a severe traumatic brain injury. The tension between "Design for Me" and "Design for All" was initially brought forward by Anderberg [1].

Today there is a range of tools and methods available for anyone who wants to develop usable systems. User centered design [14] has been around for a long time, and participatory design [11], [2], [7], [4] or versions of it is widely used. Usability testing is common practice (as in usability engineering [20]) and there are also more abstract tools such as Personas [8] to help bring developers close to the users. The importance of context has been pointed out [24], and is receiving an increasing amount of attention as more and more applications are developed for mobile devices.

Another dominating design approach is represented by the Design for All (European), Universal Design (American) and Inclusive Design (British) family of related approaches. They are strongly rooted in Ergonomics and Human Factors [10] and are based on mainstream solutions in standard products and environments. The goal of Universal Design is to design "products and environments to be usable by all people, to the greatest extent possible, without the need for adaptation or specialized design" [23]. This focus has strong political overtones and attempts to include the individual while striving for solutions on a broad level [19]. Universal Design rests on the notion that a diversity of people demands a diversity of ways to achieve equal results and 
strives towards creating an inclusive flexibility, supporting all people in fulfilling their needs, wishes and dreams. Hence, Universal Design highlights the connection between flexibility and equality. How to best achieve this flexibility is still up for debate.

Although user centered approaches involve users and situations, and often explore individual cases [13], we argue in this paper that there is often an underlying assumption that to be able to design useful systems one needs to get an understanding of the "average user" - we see no point in listing all studies where it is reported that a certain (preferably large) number of users participated in studies performed to evaluate the usability of existing or future technology.

So, although there is an increasing use of ethnologically inspired methods for observing and involving users, we suggest that there also is a common underlying assumption which states that if you understand average users and average situations you will get designs suitable for a wide range of users and situations. Newell et al. [19] highlight the need for user-sensitive inclusive design and stress the need for developers and designers to establish methods and methodology to achieve a real empathy with their user groups.

In this paper we take our inspiration from work with developing assistive solutions, and suggest that it may be fruitful to question this underlying assumption and consider what we, inspired by Anderberg [1], call "design for me".

To make our case, we start with a concrete example.

\section{Example}

Our example comes from the development of an assistive device for a teenage girl who sustained a severe head injury when she was kicked by a horse. She was unable to speak, and her mobility was extremely limited. With difficulty, she was able to move the little finger on her right hand. The parents of this girl contacted our research team asking for "a tool that will enable our daughter to say yes or no". The first device, called the Minimeter [5], was a computer-based communication tool that recorded extremely small movements of the little finger. The girl in question only needed to wear a rubber thimble with a small magnet. The second step in this development was to change from using a small magnet to making use of a video camera to decode facial expressions and head movements (Fig 1). 


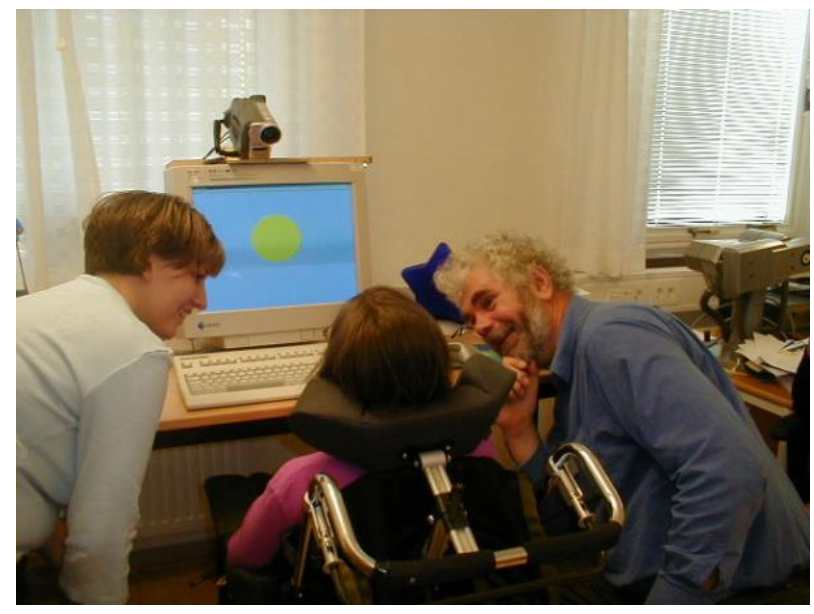

Fig. 1. The Minimeter system.

The product was developed in close collaboration with the girl and her family. After a working system had been designed, it became obvious that there were more users who needed this type of technology, and smaller adjustments were made in order to adapt the system to different users.

The technological and educational advances have been user guided: the individual has been the driving force. Improvements have progressed hand in hand with ongoing user trials. All aspects have been individually adapted to each person's very special abilities and limitations. But the reason for using this example in the present article is that which was designated for one user has proven to be useful for another (with only minor modifications). In this way, instead of starting with designing for many users at once, we started with designing for a single user and then expanded our concept to include a larger target group.

The project went on for more than ten years, and we observed how the assistive system came to wider and wider use. What started as a highly specialized system targeted at one particular girl has, as the system has matured and gotten more and more robust and flexible, come to be used by about twenty other persons with similar disabilities. We learnt a lot during the development, such as the importance of continuous feedback, that have influenced other projects on assistive technology and what we focus on also when teaching and doing research on Universal Design.

\section{Why is this relevant?}

Before discussing more in detail, the methodological implications of the suggested shift of perspective, we start by discussing why this rather extreme example from the assistive technology sector is relevant to a wider audience. 
When designing for persons with special needs there are a couple of facts that become very obvious:

1) The developer is typically not the user. As a designer or developer you cannot use yourself as a reference - you have to work very close to real users.

2) The situation the developer is in while doing the development is usually very different from the situation the user is in when using the system. Thus you explicitly have to consider how to bring the real context of the user into the development process.

Both these observations are really valid for most development work. Although on a theoretical level most developers are aware that they are not typical users (point 1), it is still common to test novel designs "in house" and/or with colleagues. Point 2 becomes particularly relevant for the development of mobile systems. The developer is usually seated in front of a desk, while the user of the mobile system may be walking, cycling, driving etc. Thus, we argue that there is a strong link between HCI in general and the assistive sector, not only in that developers of assistive systems use methods used also by non-assistive sector, but also that it should be fruitful for designers everywhere to take a closer look at methods and techniques used when developing assistive systems.

\section{Design for me}

With the above in mind we are suggesting designers and developers should consider methods where the design process starts with one person. In the process a design which really suits this person should be developed - and once a working design is reached this may then be extended to encompass more users. With this suggestion we are not thinking of just an interface element - we are talking about a full application designed to suit a single person, "me" [1]. If we compare this to the usual design methods, we could say that using this perspective ensures that the product at least fits one person really well. The usual design methods on the other hand, can be expected to lead to a design which is hopefully reasonably ok on an average level, but which may not fit anyone perfectly.

In addition, users with special needs may serve as extreme [3] and inspiring cases helping developers consider alternative solutions and to think "out of the box".

"If we understand what the extremes are, the middle will take care of itself"

(Dan Formosa, PhD, Smart Design, from the documentary "Objectified")

By now, there are several established concepts pointing towards the benefits and values of bringing in the informative far ends of user spectrums into design processes, such as extreme users [6] and lead users [18], [17]. Design for me offers a starting point that engages deeply in people's lived perspectives [16] and is initially targeted at just one person. Designing for one person has its virtues in itself. At the same time, it relates not only to the tension between the extreme and the average, but also to the tension between 
what's special and mainstream. Over time, knowledge gained from designing for several "one persons" can be utilized in broader approaches in creating an understanding of what flexibility is needed in creating useworthy solutions for all. The user's perspective is still just as extreme, "me", but it then also becomes part of mainstream flexibility.

\section{Discussion}

It is well known that it is important to bring real people and contexts into the design process. At the same time it is usually costly to get to know a large number of users and situations - and in industrial practice time saving methods such as Personas [8] are often used. While a well-constructed Persona can contain much useful information about the users it is also on some level an average construct. The kind of surprises (and design inspiration) generated by a real person and his or her lived perspective is usually lost in the process - typical personas are after all constructs synthesized from several persons. An additional problem with personas is the personal focus. In real life the abilities and preferences of a person depends on the situation (as is noted in situated design [15]) as well as on the personality. An obvious example is how a person on the move may be considered to be situationally impaired [22]. It could be argued that a combination of personas and scenarios may be the solution, but again: both are fictional - or at least filtered - versions of the reality.

If we turn to the more user centered and participatory design tradition it is clear that the above problems are avoided - although, as was observed initially, it can be very costly and time consuming to involve many users in real life situations. Living labs [9] may be one way around this hurdle, but living labs take time and effort to establish and maintain. We also question the assumption implicit in many works in this field, which is that it is better the more users you involve. As we argued above, there is a risk that by combining several persons and situations you may end up filtering away features rated high by some and low by some in favor of features rated average by everyone.

Although it is not uncommon in user centered design approaches to do small scale design activities with one or a few users, we are arguing that these are often left too early in favor of studies and activities involving more users (and where averaging/filtering takes place). We have found it useful to keep the "for me" perspective longer in order to be able to get a deeper and richer understanding of the design space, the user and the context/situation.

To start the design process with designing for a single person, understanding this person in detail, solves some of the above problems. The design team gets access to the full complexity resulting from a real person in real situations - and since only one user is involved the cost/effort involved is easier to manage. With one person involved it becomes easier to observe this kind of behaviors noted in [12] as well as to learn from them and iterate the design. In some cases, for instance when working with persons with profound disabilities, "design for me" might be the only starting point feasible. 
The obvious counter argument is the risk of choosing the wrong starting point. Just like in all other iterative design processes, if you start at the wrong point you may never converge to a good solution. In addition, there is also the risk of getting stuck in a local minimum.

Thus, we are not suggesting this as the only method that can be used when discussing design and development processes. What we argue is that a "design for me" approach can provide a design team with a valuable additional tool in their methodological toolbox, and that such a tool may provide important input which otherwise might be hard to obtain.

\section{Conclusion}

In this paper we have outlined how starting from design for a single user can be an alternative approach for achieving useful and useworthy designs. Compared to "design for one" [21] where one designs for many but strive to adapt to the individual, our approach is conceptually opposite: we suggest starting with one person and then extending to more.

After more than twenty years of research together with people with multiple and profound disabilities, "design for me" is by now a well-established approach within our research department. It is often used in combination with other activities as part of larger research designs or as part of studies built on several cases. We argue that changing the perspective from "average design" to "design for me" may provide insights helpful for developers and designers, insights that otherwise would be lost. We are not proposing our method as a silver bullet recipe solving all usability problems but we feel the "design for me" perspective may provide substantial benefits, particularly within the assistive field where it will contribute to enhancing state-of-theart.

More work remains to be done in order to develop this method when it comes to the design of mainstream products for a mass market - the intention of this paper is simply to start this process by highlighting the values of designing for me as an end in itself and as part of striving towards inclusive, useworthy solutions for all.

\section{$7 \quad$ Acknowledgements}

We want to thank everyone involved in the Minimeter project. In addition we want to thank NordForsk for funding the ActivAbles project and the EU for funding the STARR project.

\section{References}

1. Anderberg, P.: FACE-Disabled people, Technology and Internet. Lund university (2006). 
2. Bødker, S. et al.: A UTOPIAN experience: On design of powerful computerbased tools for skilled graphic workers. In: Computers and Democracy. p. 25 (1987).

3. Bødker, S. et al.: Creativity, cooperation and interactive design. Proc. 3rd Conf. Des. Interact. Syst. Process. Pract. methods, Tech. 252-261 (2000).

4. B Bdker, S., Iversen, O.S.: Staging a Professional Participatory Design Practice - Moving PD beyond the Initial Fascination of User Involvement. Proc. Second Nord. Conf. Human-Computer Interact. January, 11-18 (2002).

5. Breidegard, B.: Doing for understanding - on rehabilitation engineering design. Lund university (2006).

6. Brown, T., Katz, B.: Change by design. J. Prod. Innov. Manag. 28, 3, 381-383 (2011).

7. B $\quad$ dker, S. et al.: Cooperative Design: Techniques and Experiences From the Scandinavian Scene. In: Readings in Human-Computer Interaction. pp. 215224 (1995).

8. Chang, Y. et al.: Personas: from theory to practices. Nord. '08 Proc. 5th Nord. Conf. Human-computer Interact. Build. Bridg. 439-442 (2008).

9. Dell'Era, C., Landoni, P.: Living Lab: A Methodology between User-Centred Design and Participatory Design. Creat. Innov. Manag. 23, 2, 137-154 (2014).

10. Dong, H.: Shifting Paradigms in Universal Design. In: Universal Access in Human Computer Interaction. pp. 66-74 (2007).

11. Ehn, P.: Work-oriented design of computer artifacts. Umeå University (1988).

12. Gaver, W. et al.: Anatomy of a failure: How we knew when our design went wrong, and what we learned from it. SIGCHI Conf. Hum. Factors Comput. Syst. 2213-2222 (2009).

13. Gaver, W.W. et al.: Cultural probes and the value of uncertainty. interactions. $11,5,53$ (2004).

14. Gould, J.D., Lewis, C.: Designing for usability: key principles and what designers think. Commun. ACM. 28, 3, 300-311 (1985).

15. Greenbaum, J., Kyng, M.: Introduction: situated design. In: Design at work. pp. 1-24 L. Erlbaum Associates Inc. Hillsdale, NJ, USA (1992).

16. Hedvall, P.-O.: The Activity Diamond - Modeling An Enhanced Accessibility. Lund University (2009).

17. von Hippel, E.: Lead Users: A Source of Novel Product Concepts. Manage. Sci. 32, 7, 791-805 (1986).

18. Luthje, C., Herstatt, C.: The Lead User method: an outline of empirical findings and issues for future research. R D Manag. 34, 5, 553-568 (2004).

19. Newell, A.F. et al.: User-Sensitive Inclusive Design. Univers. Access Inf. Soc. 10, 3, 235-243 (2011).

20. Nielsen, J.: Usability Engineering. (1993).

21. Ringbauer, B. et al.: From "Design for all" towards "Design for one": a modular user interface approach. In: C., S. (ed.) Universal Acess in Human Computer Interaction. Coping with Diversity. UAHCI 2007. Lecture Notes in Computer Science, vol 4554. Springer, Berlin, Heidelberg (2007).

22. Sears, A. et al.: When computers fade: Pervasive computing and situationally 
induced impairments and disabilities. Proc. HCI Int. 2, 1298-1302 (2003).

23. Story, M. et al.: The Universal Design File: Designing for People of All Ages and Abilities. Des. Res. Methods J. 1, 5, 165 (1998).

24. Wixon, D. et al.: Contextual design: an emergent view of system design. In: Proceedings of the SIGCHI conference on Human factors in computing systems Empowering people - CHI '90. pp. 329-336 (1990). 